\title{
Pyrolysis characteristics and thermal kinetics of expanded polystyrene (EPS) and styrene-methyl methacrylate (St-MMA) copolymer in LFC process
}

\author{
Xi Li', Ya-jun Yin ${ }^{1}$, * Jian-xin Zhou' ${ }^{1}$, Xu Shen ${ }^{1}$, Ming-guo Xie ${ }^{2}$, Wei Liu ${ }^{2}$ \\ 1. State Key Laboratory of Materials Processing and Die \& Mould Technology, Huazhong University of Science \& Technology, Wuhan 430074, \\ China. \\ 2. Hefei Casting and Forging Plant of Anhui Heli Co., Ltd., Hefei 230022, China.
}

\begin{abstract}
The pyrolysis behaviors of foam patterns have critical influences on fluid morphology and defect formation in Lost Foam Casting (LFC). The pyrolysis behaviors of expanded polystyrene (EPS) and styrenemethyl methacrylate (St-MMA) foams were compared using synchronous thermal analysis (STA), which was

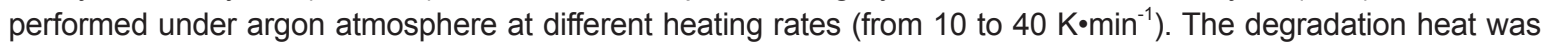
calculated by integrating DSC curves. Results show that the calculated degradation heat of St-MMA $\left(605.28 \mathrm{~J} \cdot \mathrm{g}^{-1}\right)$ was significantly lower than that of EPS $\left(706.71 \mathrm{~J}^{\circ} \mathrm{g}^{-1}\right)$. Furthermore, the non-isothermal iso-conversional method was used to determine the pyrolysis apparent activation energies of EPS and St-MMA, and results show that the

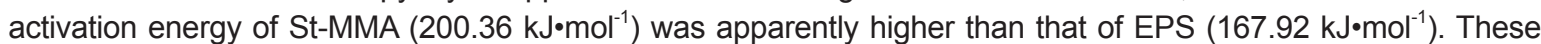
calculated results indicate that the weight loss rate of EPS is greater than St-MMA in the pyrolysis process. In addition, the apparent activation energies at various pyrolysis stages demonstrate that the pyrolysis reactions of EPS and St-MMA may involve physical and chemical changes in the decomposition layer of the LFC process.
\end{abstract}

Key words: lost foam casting; EPS, St-MMA; pyrolysis characteristics; pyrolysis kinetics
CLC numbers: TG221 ${ }^{+} 1$
Document code: A
Article ID: 1672-6421(2018 06-428-08

L ost foam casting, a near net shape and green casting technology, have various advantages, like high precision, high surface quality, environmental cleanliness, simple process and so on ${ }^{[1-4]}$. However, in ordinary sand casting, the foam would experience complex physical and chemical reactions with gasification and decalescence in the high temperature effect of molten metal during the filling process. These reactions will decrease temperature rapidly in the metal front and produce backpressure causing a huge impact on filling and even causing casting defects ${ }^{[5-8]}$.

In order to further understand the filling mechanism of lost foam casting, a great number of studies have been made to explore the pyrolysis characteristics and thermal kinetics of different kinds of foam patterns. Shivkumar S. et al. ${ }^{[9,10]}$ have investigated foam degradation of EPS and EPMMA since the 1980s. They used scanning electron

\footnotetext{
*Jian-xiu Zhou
}

Male, born in 1975, Professor, Ph.D. His research interests mainly focus on the casting process, especially on lost foam casting and casting process simulation.

E-mail: zhoujianxin@mail.hust.edu.cn

Received: 2018-04-23; Accepted: 2018-07-30 microscopy (SEM), differential scanning calorimetry (DSC) and thermogravimetric analysis (TGA) to obtain the effect of foam density and foam bead structure in the pyrolysis process on metal filling. Dong et al. ${ }^{[1]}$ applied gas chromatography to reveal the pyrolysis characteristics of three kinds of foams including EPS, EPMMA and St-MMA, finding that the main products of the three foams in pyrolysis processes were all polymer monomers, and the pyrolysis of EPMMA and St-MMA produced a great amount of small molecules reducing gas with a flame retardant effect on magnesium alloy. Zhou et al. ${ }^{[12]}$ discovered that the primary products of polystyrene pyrolysis were styrene monomer, dimer and trimer, and raising temperature would promote monomer production. Jiao at el. ${ }^{[13]}$ determined the thermal degradation kinetics and reactants of PU, XPS and EPS foams by using thermogravimetric (TG) and simultaneous thermal analysis (STA) coupled with mass spectrometry and Fourier transform infrared spectroscopy (TG-DSC-MS-FTIR). They found that the degradation processes of the three materials were different: EPS had a single weight loss process, XPS was divided into two stages, and the PU degradation process was more complex and composed of three 
stages. Zeng et al. ${ }^{[14]}$ used a non-linear iso-conversional method to attest a kinetic model for polystyrene pyrolysis. Pravin Kannan ${ }^{[15]}$ designed an experimental device to testify a kinetics model for EPS pyrolysis, suggesting that the kinetics of EPS pyrolysis are controlled by reaction at low temperature and heat transfer at high temperature. A non-isothermal kinetic equation was used to study the pyrolysis kinetics of St-MMA pre-expansion beads under oxidative and non-oxidative conditions by Hamid Reza Azimi et al. ${ }^{[16-18]}$, who found that the pyrolysis rate of St-MMA was lower than that of EPS.

Pyrolysis characteristics include pyrolysis mass loss, volatiles, pyrolysis heat and so on. Nevertheless, most researchers focus on the mass loss and thermal kinetics of different foams, and little research has been carried out on degradation decalescence changes and speculating reactions. In this study, the pyrolysis characteristics of EPS and St-MMA foams were studied systematically by measuring weight loss and decalescence. Foam samples were treated specially, including compressing and cutting, to measure mass and heat loss accurately. The degradation heat of the two foams was calculated and compared, and the thermal kinetics of the two foams were determined using the iso-conversional method. Furthermore, the degradation reactions associated with weight loss were derived based on the activation energy at each stage. By investigating the pyrolysis characteristics of EPS and St-MMA foams, the research result lays the foundation for the accurate prediction of mold filling process as well as provides guidance for the improvement of casting quality.

\section{Experimental}

EPS and St-MMA foam patterns were made with white closed honeycomb (Fig. 1). Thermal decomposition characteristics and kinetics of EPS and St-MMA were investigated with a Netzsch STA449F3 thermal analyser, including thermogravimetric analysis (TG) and differential scanning calorimetry (DSC).

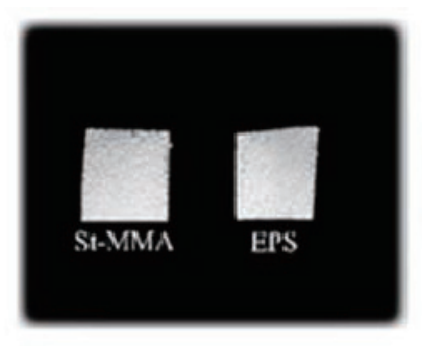

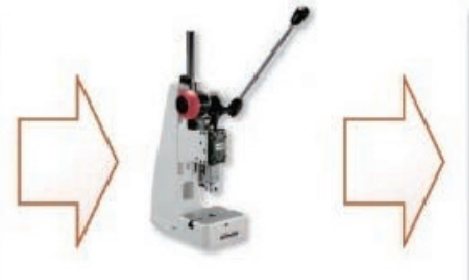

Tabletting

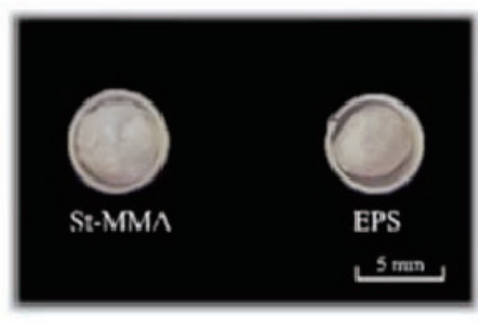

Fig. 1: St-MMA and EPS foam patterns

In order to mimic the vacuum condition and decrease the temperature gradient inside the foam during the pyrolysis process, the EPS and St-MMA foam patterns were compressed under a pressure of $40 \mathrm{MPa}$ for $5 \mathrm{~min}$, and the air inside the foam cell was discharged as much as possible. Then, the foam samples were tableted by a tableting machine before the foams were cut into crucible-sized round flakes ( $5 \mathrm{~mm}$, Fig. 1) in order to make proper contact with the crucible. Each kind of foam was divided into four groups with different heating rates of 10$40 \mathrm{~K} \cdot \mathrm{min}^{-1}$ in the synchronous thermal analyzer. Considering the foam decomposition temperature is lower than $600{ }^{\circ} \mathrm{C}$, the temperature range was set to $40-600{ }^{\circ} \mathrm{C}$. To mimic hypoxic conditions in the process of dry sand and negative pressure lost foam casting, argon in the flow rate of $50 \mathrm{ml} \cdot \mathrm{min}^{-1}$ was used as the buffer gas (Table 1).

Table 1: Experimental parameters

\begin{tabular}{ccccccccccc} 
Exp. & $\begin{array}{c}\text { Pressure } \\
(\mathbf{M P a})\end{array}$ & $\begin{array}{c}\text { Holding time } \\
(\mathbf{m i n})\end{array}$ & \multicolumn{4}{c}{ Heating rates $\left(\mathbf{K} \cdot \mathbf{m i n}^{-1}\right)$} & \multicolumn{2}{c}{$\begin{array}{c}\text { Temperature range } \\
\left({ }^{\circ} \mathbf{C}\right)\end{array}$} & $\begin{array}{c}\text { Atmosphere } \\
\text { EPS }\end{array}$ \\
\hline 40 & 5 & 10 & 20 & 30 & 40 & $40-600$ & $\mathrm{Ar}$ \\
St-MMA & 40 & 5 & 10 & 20 & 30 & 40 & $40-600$ & $\mathrm{Ar}$
\end{tabular}

\section{Results and discussion}

\subsection{Pyrolysis characteristics of EPS and St-MMA}

According to the TG-DTG-DSC curves of EPS shown in Fig. 2 , the melting and gasification landscapes are similar at different heating rates. Due to the poor thermal conductivity between the foam sheet and the crucible, thermal hysteresis exists inside the foam. The DTG-DSC curves show that increasing heating rate would promote the melting and gasification peaks shift to higher temperature. This suggests that the temperature required for the melting and gasification of foam is dependent of heating rate.

At an early stage, the DTG curves are flat, where mass loss does not occur significantly in the foam sample. However, from room temperature to about $100{ }^{\circ} \mathrm{C}$, internal impurities reaction might involve a small heat absorption and release, leading to the fluctuation in the DSC curves. In the range of $100-350{ }^{\circ} \mathrm{C}$, a relatively gentle endothermic peak (known as "melting peak") appears, the foam sample slowly absorbs heat and melts as temperature rises. Starting from $350{ }^{\circ} \mathrm{C}$, the gasification occurs accompanied by mass loss in the foam sample. In the range of $350-500{ }^{\circ} \mathrm{C}$, two gasification peaks in the DSC curves appear while only one peak is observed in the DTG curves. This might suggest that the first gasification endothermic peak could include the melting of foam. 

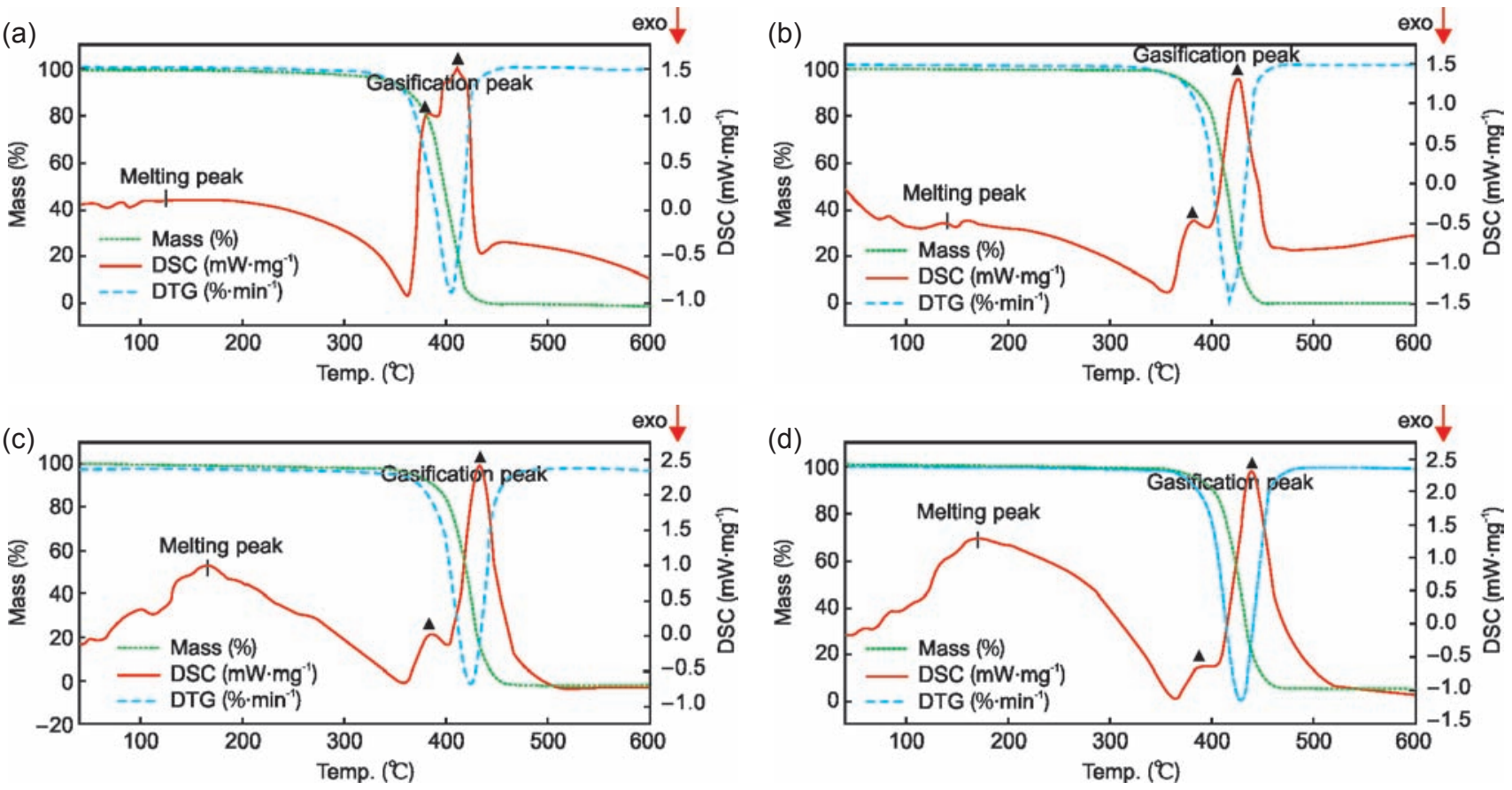

Fig. 2: TG-DTG-DSC curves of EPS at different heating rates: (a) $10 \mathrm{~K} \cdot \mathrm{min}^{-1}$, (b) $20 \mathrm{~K} \cdot \mathrm{min}^{-1}$, (c) $30 \mathrm{~K} \cdot \mathrm{min}^{-1}$, (d) $40 \mathrm{~K} \cdot \mathrm{min}^{-1}$

Figure 3 shows the pyrolysis TG-DTG-DSC curves of StMMA copolymers at different heating rates. It can be seen that the TG-DTG-DSC curves of St-MMA share a similar feature to those of EPS: raising temperature is required for the melting and gasification of St-MMA foam when increasing the heating rate. However, the TG-DSC curves of St-MMA exhibit some different features compared with those of EPS: (1) the DTG curves of St-MMA copolymer show that the foam collapses when the temperature rises to above $100{ }^{\circ} \mathrm{C}$; (2) the DSC curves of St-MMA show that gasification peaks become broader in the
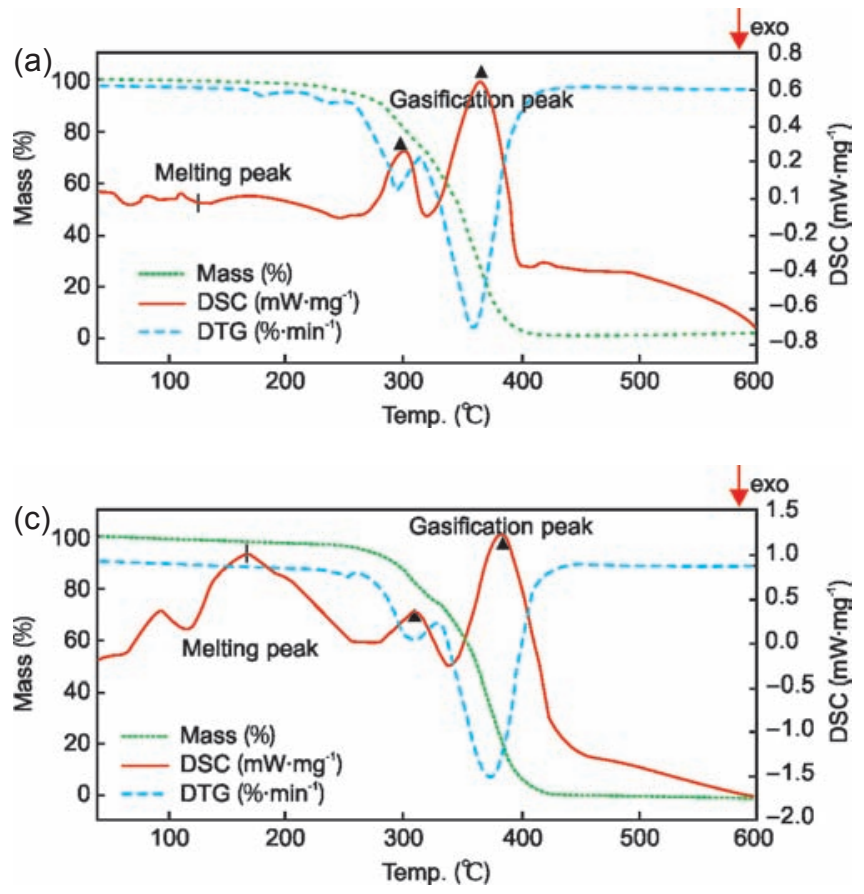

$250-330^{\circ} \mathrm{C}$ and $330-430{ }^{\circ} \mathrm{C}$ ranges; (3) the DSC curves of StMMA show that the gasification temperatures $\left(300-320^{\circ} \mathrm{C}\right)$ at the first peak are much lower than those $\left(380-390{ }^{\circ} \mathrm{C}\right)$ of EPS, suggesting that the thermal stability of St-MMA copolymer is lower than EPS.

The decomposition heat of EPS and St-MMA copolymers was calculated by integrating the DSC curves, as shown in Tables 2 and 3. According to Table 2, increasing the heating rate enhances the contribution of the melting process but reduces that of the gasification process. Similarly, Table 3 shows that the

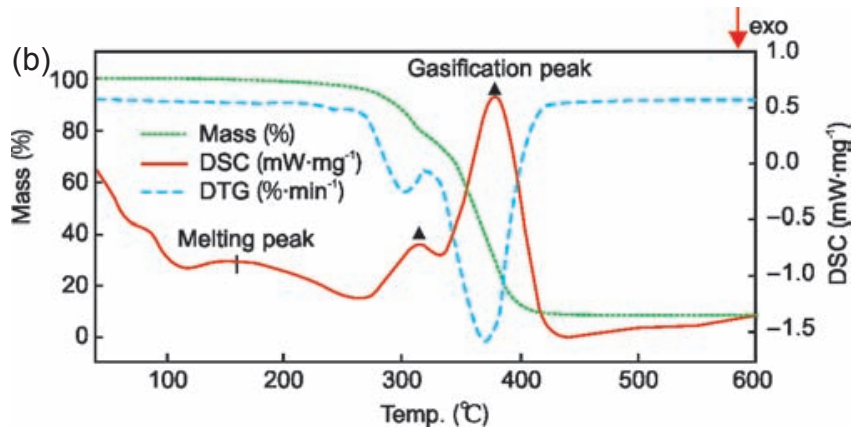

Fig. 3: TG-DTG-DSC curves of St-MMA copolymers at different heating rates: (a) $10 \mathrm{~K} \cdot \mathrm{min}^{-1}$, (b) $20 \mathrm{~K} \cdot \mathrm{min}^{-1}$, (c) $30 \mathrm{~K} \cdot \mathrm{min}^{-1}$, (d) $40 \mathrm{~K} \cdot \mathrm{min}^{-1}$

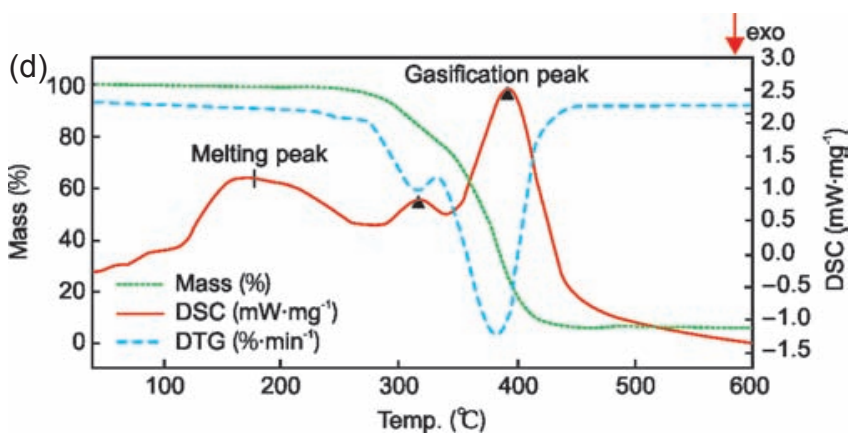


Table 2: Decomposition heat of EPS

\begin{tabular}{|c|c|c|c|c|}
\hline EPS & $10 \mathrm{~K} \cdot \mathrm{min}^{-1}$ & $20 \mathrm{~K} \cdot \mathrm{min}^{-1}$ & $30 \mathrm{~K} \cdot \mathrm{min}^{-1}$ & $40 \mathrm{~K}^{\prime} \mathrm{min}^{-1}$ \\
\hline Melting peak $\left(\mathrm{J} \cdot \mathrm{g}^{-1}\right)$ & 152.94 & 367.72 & 419.02 & 487.49 \\
\hline Gasification peak $1\left(\mathrm{~J} \cdot \mathrm{g}^{-1}\right)$ & 134.27 & 60.22 & 37.055 & 15.05 \\
\hline Gasification peak $2\left(\mathrm{~J} \cdot \mathrm{g}^{-1}\right)$ & 447.64 & 255.86 & 227.15 & 222.42 \\
\hline Sum $\left(J \cdot g^{-1}\right)$ & 734.85 & 683.80 & 683.225 & 724.96 \\
\hline
\end{tabular}

Table 3: Decomposition heat of St-MMA

\begin{tabular}{|c|c|c|c|c|}
\hline St-MMA & $10{\mathrm{~K} \cdot \mathrm{min}^{-1}}^{-1}$ & $20 \mathrm{~K} \cdot \mathrm{min}^{-1}$ & $30 \mathrm{~K} \cdot \mathrm{min}^{-1}$ & $40 \mathrm{~K} \cdot \mathrm{min}^{-1}$ \\
\hline Melting peak $\left(\mathrm{J} \cdot \mathrm{g}^{-1}\right)$ & 157.48 & 109.98 & 278.49 & 216.36 \\
\hline Gasification peak $1\left(\mathrm{~J} \cdot \mathrm{g}^{-1}\right)$ & 123.06 & 185.61 & 99.60 & 134.28 \\
\hline Gasification peak $2\left(\mathrm{~J} \cdot \mathrm{g}^{-1}\right)$ & 309.94 & 311.40 & 219.31 & 275.60 \\
\hline $\operatorname{Sum}\left(J \cdot \mathrm{g}^{-1}\right)$ & 590.48 & 606.99 & 597.4 & 626.24 \\
\hline
\end{tabular}

contribution of the melting process increases with the raise in heating rate basically, although there are some slight decreases at the heating rate of $20 \mathrm{~K} \cdot \mathrm{min}^{-1}$. However, in the pyrolysis process of St-MMA copolymer, the melting and gasification processes cannot be separated well, leading to the heating rate independence of the gasification process.

The average decomposition heats of EPS and St-MMA were measured to be $706.71 \mathrm{~J} \cdot \mathrm{g}^{-1}$ and $605.28 \mathrm{~J} \cdot \mathrm{g}^{-1}$, respectively, giving a difference of $101.43 \mathrm{~J} \cdot \mathrm{g}^{-1}$ between EPS and St-MMA. This is consistent with the calculations of degradation heat according to Eq. (1), showing that the degradation heat of EPS foam is

$$
P C T=\frac{\Delta Q(\mathrm{EPS})-\Delta Q(\mathrm{St}-\mathrm{MMA})}{\Delta Q(\mathrm{St}-\mathrm{MMA})} \times 100 \%
$$

$16.76 \%$ higher than that of St-MMA.

where $P C T$ represents the increase percentage of EPS decomposition heat compared with that of St-MMA (\%), $\Delta Q$ represents decomposition heat of EPS or St-MMA $\left(\mathrm{J} \cdot \mathrm{g}^{-1}\right)$.

In an actual production of lost foam casting, it is necessary to consider the foam heat absorption of the filling front as well as the accurate choice of different thermodynamic parameters for different kinds of foams. In particular, pouring temperature could be determined in light of the decomposition heat of various foam patterns.
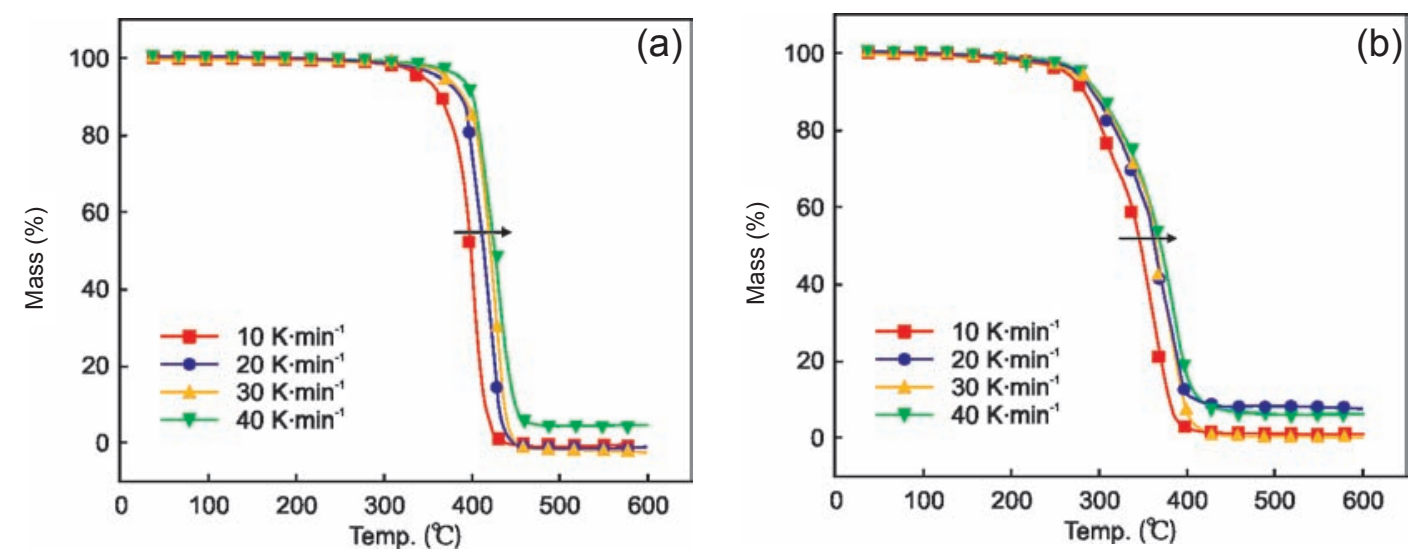

Fig. 4: TG curves of EPS and St-MMA ((a) - EPS, (b) - St-MMA)
The pouring temperatures of EPS and St-MMA were calculated on the basis of decomposition heat by use of Eq. (2):

$$
\Delta t=\frac{\rho_{f} \Delta Q}{\rho_{l} C_{p}}
$$

where $\Delta t$ represents pouring temperature difference $\left({ }^{\circ} \mathrm{C}\right), \rho_{f}$ and $\rho_{l}$ correspond to foam appearance density and metal density $\left(\mathrm{kg} \cdot \mathrm{m}^{-3}\right)$, respectively, $\Delta Q$ and $C_{p}$ indicate foam degradation heat $\left(\mathrm{J} \cdot \mathrm{kg}^{-1}\right)$ and specific heat capacity $\left(\mathrm{J} \cdot \mathrm{kg}^{-1} \cdot{ }^{\circ} \mathrm{C}^{-1}\right)$, respectively. Thus, the pouring temperature required for St-MMA foam is lower than that for the EPS foam since the decomposition heat $\Delta Q$ is proportional to the pouring temperature $\Delta t$. In this way, the St-MMA copolymer has an advantage over the EPS copolymer as the foam pattern because the energy waste can be reduced and the structure coarsening caused by the high temperature during the casting solidification process can be avoided.

\subsection{Differential thermogravimetric curves of EPS and St-MMA foams}

According to the TG curves in Fig. 4, the temperatures for maximum mass loss in the EPS and St-MMA foams were $500{ }^{\circ} \mathrm{C}$ and $470{ }^{\circ} \mathrm{C}$, respectively. In general, a higher heating rate would result in a higher residue content after pyrolysis because the 

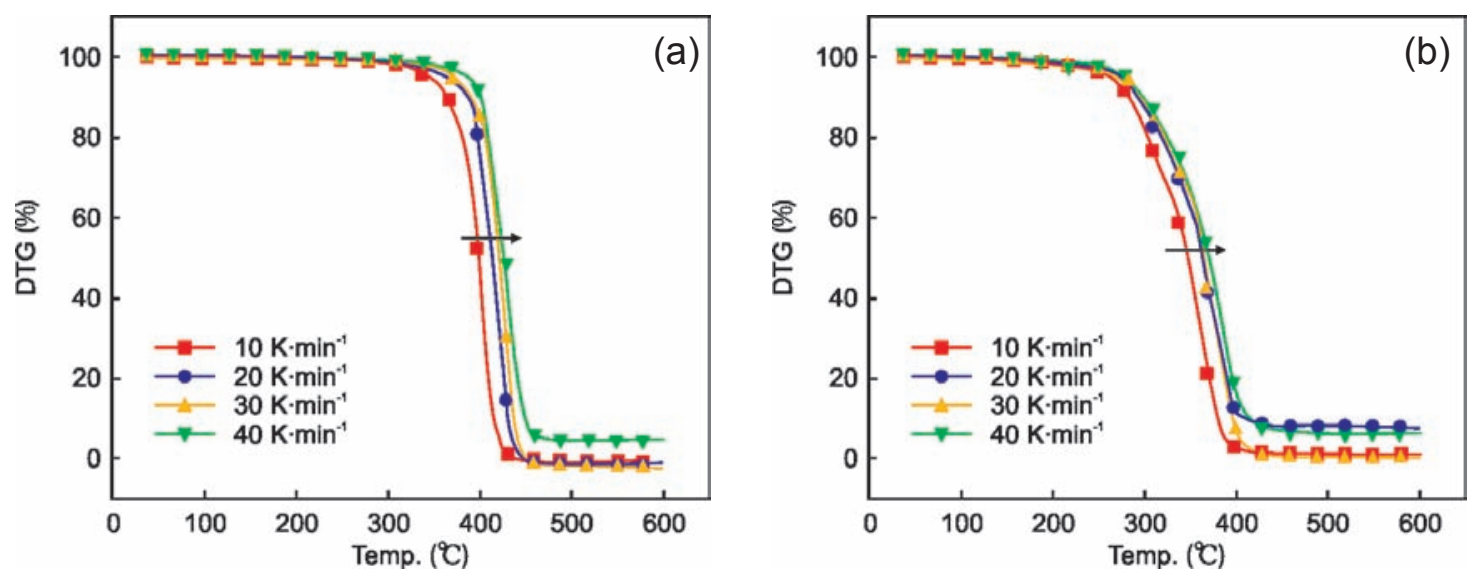

Fig. 5: DTG curves of EPS and St-MMA: (a) EPS, (b) St-MMA

foams may not be fully pyrolyzed to produce carbon black and other substances at a higher heating rate.

Figure 5 shows the DTG curves of EPS and St-MMA thermal decomposition at different heating rates. In Fig. 5(a), it was found that the gasification of EPS foam starts at $310^{\circ} \mathrm{C}$, and ends around $500{ }^{\circ} \mathrm{C}$ (black real line). The temperature for maximum weight loss rate is close to $410^{\circ} \mathrm{C}$ and the maximum weight loss rate of EPS increases with the heating rate. Although the entire pyrolysis process for EPS is a single weight loss progress displayed from its DTG curve, the weight loss rate changes slightly in a small range at the beginning of the pyrolysis. When reactions occur in the EPS pyrolysis, the starting temperature for breaking the chemical bonds in molecules is apparently influenced by the heating rate.

The gasification of St-MMA copolymer starts at $226{ }^{\circ} \mathrm{C}$ and ends around $470{ }^{\circ} \mathrm{C}$, as shown in Fig. 5(b). In comparison with EPS pyrolysis, the initiation temperature of St-MMA pyrolysis is lower, the temperature range of breaking chemical bonds is larger, and the maximum weight loss rate is reduced by half. In light of DTG curves of St-MMA, the overall weight loss of St-MMA copolymer was divided into three different stages (indicated by I, П and Ш, respectively).

At Stage I, a weight loss of about $3 \%$ appears below $224{ }^{\circ} \mathrm{C}$ because of the vaporization of the blowing agent and volatile low molecular weight compounds (such as circular molecules) or the volatilization of moisture inside the foam. At Stage $\Pi$, the temperature range is $224-310{ }^{\circ} \mathrm{C}$ and the weight loss is $10 \%-$ $14 \%$. The breaking of end C-C bond of polymer chain controlled by rapid unzipping mechanism may result in the formation of a certain amount of monomer. At Stage $\amalg$, which is the main pyrolysis reaction stage, the temperature range is $310-470{ }^{\circ} \mathrm{C}$ and the weight loss is about $85 \%$. The reaction rate at Stage Ш was higher than at the other two stages, and various reactions took place and different volatile products were produced in this stage.

\subsection{Thermal kinetics of EPS and St-MMA}

Since the reactions in EPS and St-MMA pyrolysis normally occur in solid-state, these reactions should involve multiple steps instead of one-step in the degradation processes ${ }^{[16]}$.
Therefore, a model-free method is applied to study the thermal kinetics of different kinds of foams and to explore the reaction mechanisms, including the calculations of thermal kinetics parameters and the derivation of pyrolysis reactions. According to the principle of non-isothermal kinetics, the thermal kinetic model of EPS and St-MMA copolymer has been established under non-isothermal and heterogeneous conditions. By using the integral iso-conversional method ${ }^{[19]}$, empirical activation energy $E a$ is calculated under the condition of uncertain reaction mechanism function to avoid the error due to the choice of reaction mechanism function.

For solid pyrolysis reactions, the non-isothermal kinetics equation ${ }^{[20-22]}$ is given as:

$$
\beta \frac{d \alpha}{d T}=k(T) f(a)=A e^{-\frac{E a}{R T}} f(a)
$$

where,

$\beta$ - heating rates $(d T / d t),{ }^{\circ} \mathrm{C} \cdot \mathrm{min}^{-1}$;

$\alpha$-reaction conversion, $\%$;

$k(T)$ - reaction rate constant;

$R$ - Gas constant, $\mathrm{J} \cdot \mathrm{mol}^{-1} \cdot \mathrm{K}^{-1}$;

$T$ - thermodynamics temperature, $\mathrm{K}$;

$E a$ - apparent activation energy, $\mathrm{kJ} \bullet \mathrm{mol}^{-1}$;

$A$ - pre-exponential factor, s-1;

$f(\alpha)$ - differential form mechanism function.

By using the integral iso-conversional method, KAS (Kissinger-Akah-Sunose) ${ }^{[23,24]}$ and Ozawa equations ${ }^{[25-27]}$ are obtained, respectively:

$$
\begin{gathered}
\ln \frac{\beta}{T^{2}}=\ln \left(\frac{A E a}{G(\alpha) R}\right)-\frac{E a}{R T} \\
\ln \beta=\ln \left(\frac{0.0048 A E a}{G(\alpha) R}\right)-\frac{E a}{R T}
\end{gathered}
$$

where, $G(\alpha)$ is the integral form mechanism function.

Since the KAS and Ozawa equations are limited to the range of $q\left(q=E_{a} / R T\right)$, the non-linear iso-conversional method can be used to take Senum-Yang second-order approximation ${ }^{[28]} ; h(q)$ and $H(q)$ slowly change with $q$, so that it is not limited by the scope of $q$. 


$$
\begin{gathered}
h(q)=\frac{q^{4}+18 q^{3}+88 q^{2}+96 q}{q^{4}+20 q^{3}+120 q^{2}+240 q+120} \\
H(q)=\frac{e^{-q} h(q) / q^{2}}{0.0048 e^{-1.0516 q}}
\end{gathered}
$$

where $h(q)$ and $H(q)$ represent the integral approximation parameters of KAS and Ozawa method, respectively.

The empirical activation energy $E a$ for the thermal decomposition of EPS and St-MMA foams under different conversion rates $\alpha$ can be obtained by linear regression of $\ln \beta$ or $\ln \left(\beta / T^{2}\right)$ and $1 / T$ by least squares method according to Eq. (4) or (5). The Ea values at different conversion rates are calculated iteratively according to Eq. (6) and (7) by the KAS-iteration and Ozawa-iteration methods and then by Eq. (8) or (9) until Ea(i) $E a(i-1)<0.1 \mathrm{~kJ} \cdot \mathrm{mol}^{-1}$.

$$
\ln \frac{\beta}{h(q) T^{2}}=\ln \left(\frac{A E a}{G(\alpha) R}\right)-\frac{E a}{R T}
$$

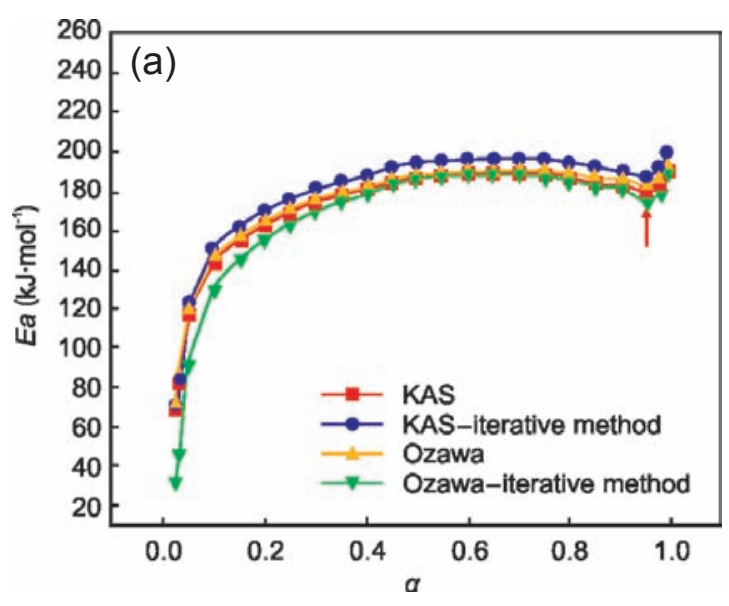

$$
\ln \frac{\beta}{H(q)}=\ln \left(\frac{0.0048 A E a}{G(\alpha) R}\right)-1.0516 \frac{E a}{R T}
$$

The effective activation energies $E a$ for thermal decomposition obtained by these four calculation methods are shown in Fig. 6 . Because the KAS and Ozawa equations introduce approximate integration of temperature, some errors could be generated. These iterative methods will make effective activation energy close to real value. The results of four methods have a similar distribution trend and the degree of dispersion is small, ensuring the accuracy of effective activation energy. Our calculations show that the effective average activation energy of polystyrene EPS foam

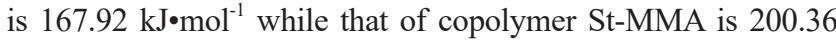
$\mathrm{kJ} \bullet \mathrm{mol}^{-1}$. Thus, the activation energy of EPS is apparently lower than that of St-MMA, indicating that the EPS foam reaction rate is larger than that of copolymer St-MMA foam under the same reaction conditions. This result is consistent with the observation that EPS weight loss rate is greater than that of St-MMA in the DTG curves of Fig. 5.

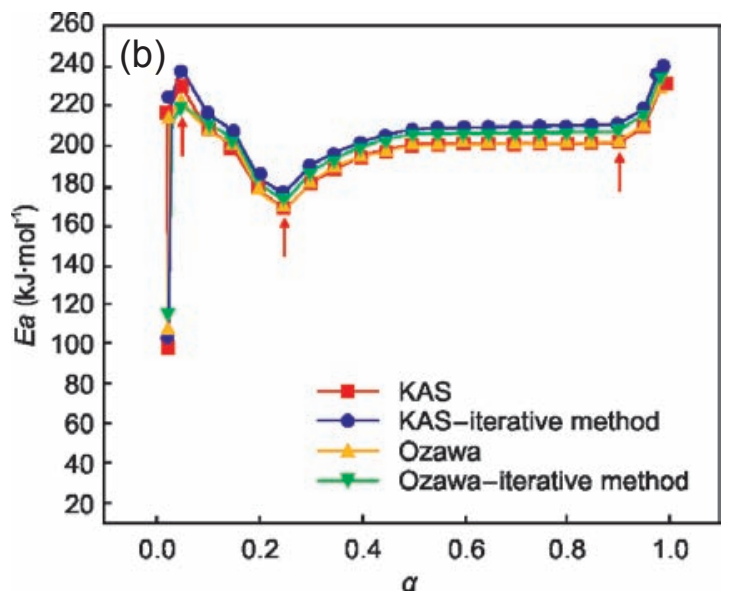

Fig. 6: EPS (a) and St-MMA (b) apparent activation energy (Ea) curves

Pyrolysis reaction processes of EPS and St-MMA copolymer could be analyzed in accordance with the curves of apparent activation energies and extent of conversion. The activation energy curves of EPS in Fig. 6(a) reveal that apparent activation energy $E a$ increases with an increase in reaction conversion $\alpha$ at $\alpha<0.5$, because of the decomposition of low molecular weight polymers and the breaking of weak bonds in the early stage of EPS pyrolysis. As the conversion rate increases, the polymer backbone starts to be broken and depolymerized. Subsequently, the $E a$ curves reach

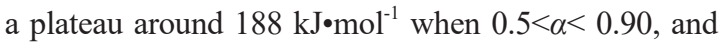
stable $E a$ suggests that the pyrolysis process involves chain initiation, chain shortening, and chain transfer reactions. The random cleavage of $\mathrm{C}-\mathrm{C}$ bond in the molecular chain produces a large amount of styrene monomer [Eq. (10), Eq. (11)] and a certain amount of oligomer, toluene, benzene and other substances. Then, $E a$ is decreased slightly when $0.90<\alpha<0.95$, due to chain termination reactions. When $\alpha>0.95$,
$E a$ suddenly rises. The reason for the rise in $E a$ is that the reactant concentration is too low and the reaction is controlled by the diffusion mechanism instead of the pyrolysis reaction.<smiles>C=Cc1ccccc1</smiles>

On the basis of Ea- $\alpha$ curves of St-MMA copolymer in Fig. 6(b), empirical activation energy $E a$ is about $100 \mathrm{~kJ}^{\circ} \mathrm{mol}^{-1}$ at the beginning of thermal decomposition reaction of St-MMA and rises dramatically with the increase of conversion $\alpha$, due to the rapid fracture of weak bonds and some of the circular molecules in St-MMA copolymer. Empirical activation energy $\mathrm{Ea}$ rises up to above $200 \mathrm{~kJ} \cdot \mathrm{mol}^{-1}$, because the reaction 
of volatile compound is close to complete and the activation energy increases.

When $0.03<\alpha<0.25$, empirical activation energy Ea decreases, and the polymer chain begins to be broken and depolymerized. Owing to the weak $\mathrm{C}=\mathrm{C}$ bonds at the end of the molecular chain ${ }^{[29,30]}$, the $\mathrm{C}-\mathrm{C}$ bond cleavage [Eq. (12), Eq. (13)] occurs. At the same time, the chain initiation reaction generates free radicals.
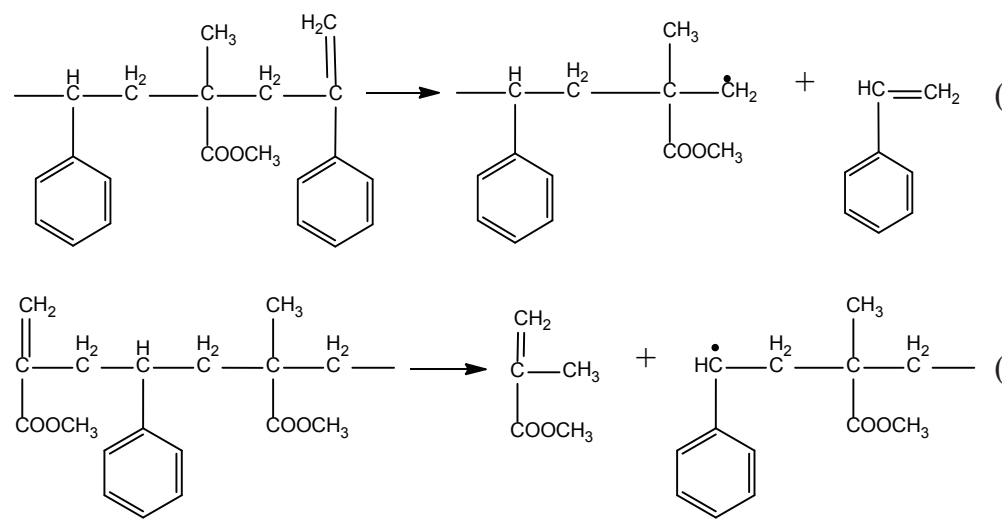

When $0.25<\alpha<0.95, E a$ rises with the increase of conversion rate, because the $\mathrm{C}-\mathrm{C}$ bonds at the end of molecular chain would be gradually broken as the reaction proceeds. Subsequently, the $\beta$-bond breakage occurs in the molecular chain ${ }^{[12]}$. This stage undergoes some chain shortening reactions and transfer reactions. According to the literature ${ }^{[31,32]}$, the pyrolysis of polystyrene PS mainly occurs in random fracture mechanism of $\mathrm{C}-\mathrm{C}$ bond while the PMMA pyrolysis mechanism is a rapid unzipping mechanism where $\mathrm{C}-\mathrm{C}$ bonds at the end of the molecular chain are broken to produce a large number of MMA monomers. Therefore, a large amount of styrene [Eq. (14)] and MMA monomers [Eq. (15)] are produced at this stage, and some small molecules (such as $\mathrm{CO}, \mathrm{CH}_{4}, \mathrm{CH}_{3} \mathrm{OH}, \mathrm{H}_{2} \mathrm{O}$, and other small molecules) are produced because of the presence of ester groups $\left(-\mathrm{COOCH}_{3}\right)$ in MMA monomer [Eq. (16), Eq. (17)]. When $\alpha>0.95$, Ea rises rapidly due to the decrease of the reactant concentration<smiles></smiles><smiles>C=Cc1ccccc1</smiles><smiles>C=CC[CH-]CC(=O)OC(=O)C(=C)C</smiles><smiles>C=C(C)C(=O)OC</smiles>

mainly controlled by the diffusion mechanism.

Based on the exponential form of the Arrehnius rate constant, a kinetic compensation effect (KCE) is supposed to be present ${ }^{[19]}$, such that a cohesive relationship exists between the activation energy $E a$ and the pre-exponential factor $A$. Apparent activation energy $E a$ varies with the change of the conversion rate, which is different from the initial activation energy concept - the energy requirement for activation of molecules is only related to the beginning and ending states. This indicates that these solid-state pyrolysis reactions are not the single elementary reaction, but multiple elementary reactions occur simultaneously or continuously.

\section{Conclusions}

The thermal analysis experiments of two kinds of foam patterns of polystyrene EPS and copolymer St-MMA were carried out in order to explore the pyrolysis characteristics and thermal kinetics of EPS and St-MMA. The following conclusions are made:

(1) The pyrolysis processes of EPS and St-MMA are both subjected to three stages: collapsing, melting, and gasification. The temperature for EPS foam gasification is higher than that of St-MMA, while the decomposition heat of St-MMA copolymer is lower than that of EPS foam. Due to the lower decomposition heat of St-MMA than that of the EPS, the pouring temperature can be reduced under the premise of avoiding casting defects such as misrun during the pouring process.

(2) With the increase of heating rate, the TG and DTG curves of EPS and St-MMA are shifted to higher temperatures. In pyrolysis, a one-stage weight loss was observed in the pyrolysis of EPS foam and a three-stage weight loss in that of St-MMA foam, followed by lower molecular weight volatile compound reaction and polymer depolymerization.

(3) The apparent activation energy $E a$ of EPS and St-MMA was calculated using the isoconversional method and the variation of $E a$ with the conversion $\alpha$ was plotted. Results show that the pyrolysis process mainly involves chain initiation, chain shortening, chain transfer, and chain termination reactions. Meanwhile, the apparent activation energy of EPS is lower than that of St-MMA, which is consistent with the observation that EPS weight loss rate is higher than that of St-MMA in TG curves. 


\section{References}

[1] Shayegh J, Hossainpour S, Rezaei M, et al. Developing a new $2 \mathrm{D}$ model for heat transfer and foam degradation in EPS lost foam casting (LFC) process. International Communications in Heat and Mass Transfer, 2010, 37(9): 1396-1402.

[2] Li Guangyu, Jiang Wenming, Fan Zitian, et al. Effects of pouring temperature on microstructure, mechanical properties, and fracture behavior of $\mathrm{Al} / \mathrm{Mg}$ bimetallic composites produced by lost foam casting process. The International Journal of Advanced Manufacturing Technology, 2016, 91(1-4):13551368.

[3] Long Wang, Nathalie Limodin, Ahmed El Bartali, et al. Influence of pores on crack initiation in monotonic tensile and cyclic loadings in lost foam casting A319 alloy by using 3D in-situ analysis. Materials Science and Engineering: A, 2016, 673: 362-372.

[4] Guler K A, Kisasoz A, Karaaslan A. A study of expanded polyethylene (EPE) pattern application in aluminium lost foam casting. Russian Journal of Non-Ferrous Metals, 2015, 56(2): 171-176.

[5] Li Jiqiang, Zhao Zhong, Fan Zitian, et al. Study on typical hole defects in AZ91D magnesium alloy prepared by low pressure lost foam casting. China Foundry, 2013, 10(4): 232-236.

[6] Ai-chao Cheng, Bo-lin Jia, Ren-fei Guo, et al. Effect of thermophysical property and coating thickness on microstructure and characteristics of a casting. China Foundry, 2017,14(1): 46-54.

[7] Jiang Wenming, Fan Zitian. Novel technologies for the lost foam casting process. Frontiers of Mechanical Engineering, 2017, 13(1): $37-47$.

[8] Xie Ming-guo, Zhu Chang-an. Construction and analysis of dynamic solidification curves for non-equilibrium solidification process in lost-foam casting hypoeutectic gray cast iron. China Foundry, 2017, 14(3): 176-183.

[9] Mehta S, Biederman S, Shivkumar S. Thermal degradation of foamed polystyrene. Journal of Materials Science, 1995, 30(11): 2944-2949.

[10] Mehta S, Shivkumar S. Thermal degradation of foamed polymethyl methacrylate in the expendable pattern casting process. Journal of Materials Engineering and Performance, 1994, 3(3): 329-333.

[11] Dong Xuanpu, Fan Zitian, Huang Naiyu, et al. Pyrolysis characteristics of foam pattern in lost foam casting of magnesium alloy. China Foundry, 2005 (2):134-137.

[12] Zhou Junbo, Qiao Yu, Wang Wenxia, et al. Formation of styrene monomer, dimer and trimer in the primary volatiles produced from polystyrene pyrolysis in a wire-mesh reactor. Fuel, 2016,182: 333-339.

[13] Jiao Lingling, Xu Guangdong, Wang Qingsong, et al. Kinetics and volatile products of thermal degradation of building insulation materials. Thermochimica Acta, 2012, 547:120-125.

[14] Zeng Wenru, Yao Bin, Zong Ruowen, et al. Study on the Relationship between the Activation Energy of Polystyrene Pyrolysis and the Conversion Rate by Nonlinear isoconvensional method. Polymeric Materials Science and Engineering, 2008(08):128-131. (In Chinese)

[15] Pravin Kannan, Joseph J Biernacki, Donald P Visco, et al. Kinetics of thermal decomposition of expandable polystyrene in different gaseous environments. Journal of Analytical and
Applied Pyrolysis, 2009, 84(2):139-144.

[16] Hamid Reza Azimi, Mostafa Rezaei, Faezeh Majidi. The nonisothermal degradation kinetics of St-MMA copolymers. Polymer Degradation and Stability, 2014, 99: 240-248.

[17] Hamid Reza Azimi, Mostafa Rezaei, Farhang Abbasi, et al. Nonisothermal degradation kinetics of MMA-St copolymer and EPS lost foams. Thermochimica Acta, 2008, 474(1-2): 72-77.

[18] Hamid Reza Azimi, Mostafa Rezaei, Farhang Abbasi. Thermooxidative degradation of MMA-St copolymer and EPS lost foams: Kinetics study. Thermochimica Acta, 2009, 488(1-2): 43-48.

[19] Sergey Vyazovkin. Isoconversional Kinetics of Thermally Stimulated Processes. Springer International Publishing, 2015.

[20] Muhamad N, Yusoff M M, Gimbun J. Thermal degradation kinetics of nicotinic acid, pantothenic acid and catechin derived from Averrhoa bilimbi fruits. RSC Advances, 2015, 5(90): 74132-74137.

[21] Naveen C, Premalatha M. Impact of blend ratio on the co-firing of post-methanated distillery effluent solid waste and low-rank Indian coal via analysis of oxidation kinetics through TGA. RSC Advances, 2016, 6(31): 26121-26129.

[22] Rezaei-Shahreza P, Seifoddini A, Hasani S. Nonisothermal kinetic analysis of nano-crystallization process in (Fe41Co7Cr15Mo14Y2C15)94B6 amorphous alloy. Thermochimica Acta, 2017, 652: 119-125.

[23] Pallab Das, Pankaj Tiwari. Thermal degradation kinetics of plastics and model selection. Thermochimica Acta, 2017, 654: 191-202.

[24] Yao Zhongliang, Ma Xiaoqian, Wang Zihuan, et al. Characteristics of co-combustion and kinetic study on hydrochar with oil shale: A thermogravimetric analysis. Applied Thermal Engineering, 2017, 110: 1420-1427.

[25] Sergey Vyazovkin, Alan K Burnham, José M Criado, et al. ICTAC Kinetics Committee recommendations for performing kinetic computations on thermal analysis data. Thermochimica Acta, 2011, 520(1-2): 1-19.

[26] Sergey Vyazovkin, Konstantinos Chrissafis, Maria Laura Di Lorenzo, et al. ICTAC Kinetics Committee recommendations for collecting experimental thermal analysis data for kinetic computations. Thermochimica Acta, 2014, 590: 1-23.

[27] Xu Changbo, Tang Lihuang, Wu Yongqiang, et al. Fast Pyrolysis of Polystyrene to Obtain Styrene at High Temperature. China Plastics, 2015, 29(05): 65-69. (In Chinese)

[28] Dhyani V, Kumar J, Bhaskar T. Thermal decomposition kinetics of sorghum straw via thermogravimetric analysis. Bioresour Technol., 2017, 245(Pt A): 1122-1129.

[29] Mao Gaobo, Cheng Shizhen, Rao Qunzhang. Study on gas evolution characteristics of pattern material in EPC Process. Special Casting \& Nonferrous Alloys, 1998(02):12-14. (In Chinese)

[30] Chao Gai, Dong Yuping, Yang Shuai, et al. Thermal decomposition kinetics of light polycyclic aromatic hydrocarbons as surrogate biomass tar. RSC Advances, 2016, 6(86): 8315483162.

[31] Vyazovkin S, Wight C A. Kinetics in solids. Annu Rev Phys Chem, 1997, 48: 125-149.

[32] Hu Rongzu. Thermal Analysis Kinetics. 2nd Edition: Science Press, Beijing, China, 2016. (In Chinese) 